\title{
Neither Menoscinae nor Lophopinae, a new genus that challenges the current classification of the Lophopidae Stål, 1866 (Hemiptera: Fulgoromorpha)
}

\author{
Menglin WANG ${ }^{1,2}$, Yinglun WANG ${ }^{1, *}$ and Adeline SOULIER-PERKINS ${ }^{3}$ \\ ${ }^{1}$ Key Laboratory of Plant Protection Resources and Pest Management of the Ministry of Education, Entomological Museum, \\ Northwest A\&F University, Yangling, Shaanxi 712100, China; e-mails: wangmenglin123@126.com, yinglunw@nwsuaf.edu.cn \\ ${ }^{2}$ Muséum national d'Histoire naturelle, Institut de Systématique, Évolution, Biodiversité, ISYEB-UMR 7205 MNHN-CNRS- \\ UPMC-EPHE, Sorbonne Universités, 57 rue Cuvier, CP 50, F-75005 Paris, France \\ ${ }^{3}$ Muséum national d'Histoire naturelle, Mécanismes adaptatifs et évolution, MECADEV-UMR 7179 MNHN-CNRS, 57 rue Cuvier, \\ CP 50, F-75005 Paris, France; e-mail: soulier@mnhn.fr
}

Key words. Fulgoroidea, Lophopidae, planthopper, Silvispina changpotou, new genus, new species, morphology, Yunnan

\begin{abstract}
The monotypic genus Silvispina M. Wang \& Soulier-Perkins, gen. n. and new species S. changpotou M. Wang \& Soulier-Perkins, sp. n. belonging to the family Lophopidae Stål, 1866, from Yunnan Province in China, is described and illustrated. The peculiarity of the first metatarsal segment of this genus is stressed and the taxonomic position of this new genus is discussed. The ornamentation and shape of metatibia and first tarsal segment (the characters that currently distinguish the subfamilies Menoscinae and Lophopinae) do not agree with either subfamily and the new genus is placed as incertae sedis in the Lophopidae. The genus Ridesa Schumacher, 1915 is removed from the family Lophopidae and placed in the Achilidae.
\end{abstract}

ZooBank Article LSID: EFD95B22-3724-4AA6-96E4-76518D8F4C8E

\section{INTRODUCTION}

The family Lophopidae was erected by Stål in 1866 with Lophops Spinola, 1839 as the type genus. It is a relatively small family of planthoppers, with 46 genera, fossils included, and 152 species worldwide (Bourgoin, 2015). It occurs in the Oriental, Afrotropical (2 genera), Australasian and Neotropical (1 genus) biogeographical regions of Wallace. Soulier-Perkins (2001) divided this family into four main monophyletic groups: Carrionia ${ }^{+}, \mathrm{Makota}^{+}, \mathrm{Bisma}^{+}$ and Sarebasa $^{+}$, using a cladistic phylogeny based on 73 morphological characters. In 2015, two new genera were described (Stroiński \& Soulier-Perkins, 2015; Soulier-Perkins \& Stroiński, 2015) and included in the matrix along with a new character. Therefore, the phylogeny was tested and the four main monophyletic groups remained with the two new genera included without disrupting the relationships between genera. Clades were referred to using the name of the basalmost taxon included followed by the sign "“+" (Amorim, 1982), such that the type genus Lophops was included in Sarebasa ${ }^{+}$. This author did not make any nomenclatural changes and left the classification as proposed by Metcalf in 1955 in his Homoptera catalogue. However, the genera Hesticus Walker, 1862 and Silvanana Metcalf, 1947 were located in an outgroup and SoulierPerkins recommended their removal from the Lophopidae. Gnezdilov (2009) placed Silvanana in the Ricaniidae and kept Hesticus incertae sedis. Emeljanov (2014) described two new tribes and reorganized Metcalf's classification so that it more closely conformed to the 2001 phylogenetic results of Soulier-Perkins, as can be seen in Table 1. Thus, the subfamily Menoscinae Melichar, 1915 contains 4 tribes (Carrioniini Emeljanov, 2014, Virgiliini Emeljanov, 2014, Menoscini Melichar, 1915 and Acarnini Baker, 1925) and the Lophopinae Stål, 1866 contains 2 tribes (Elasmoscelini Melichar, 1915 and Lophopini Stål, 1866). The Lophopinae contains all the genera of Sarebasa ${ }^{+}$plus Katoma Baker, 1925. The tribes Carrioniini and Virgiliini correspond to the groups Carrionia ${ }^{+}$and $\mathrm{Makota}^{+}$, respectively, and as such are monophyletic lineages (Table 1).

\footnotetext{
* Corresponding author; e-mail: yinglunw@nwsuaf.edu.cn
} 
Table 1. Classifications of Metcalf (1955) and Emeljanov (2014), and the monophyletic groups of Soulier-Perkins (2001) and Soulier-Perkins \& Stroiński (2015) (marked by a "+" sign). The genera currently not included in the Lophopidae or placed in synonymy are indicated by the "•" and "o" signs, respectively, placed before the genus name; the uncoloured table cells correspond to genera that were either not described when the phylogeny or the classifications were provided, not included in the respective study, or placed in synonymy at that time. The genus Ridesa Schumacher, 1915 is herein transferred to Achilidae (see Discussion).

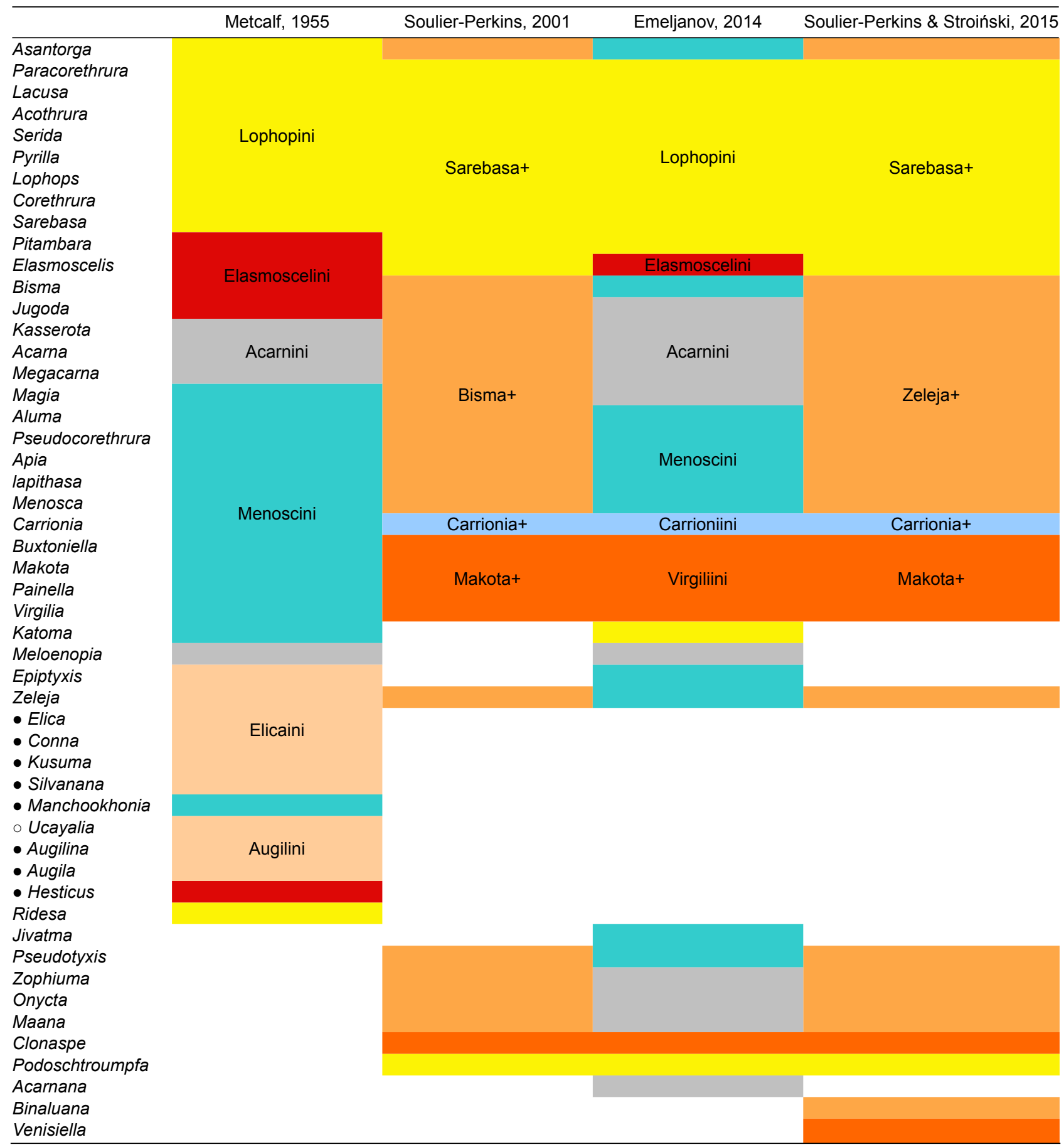

\section{MATERIAL AND METHODS}

\section{Material}

The specimen studied is deposited in the Entomological Museum of Northwest A\&F University (NWAFU), Yangling, Shaanxi, China.

\section{Preparation and observation}

The abdomen of the specimen was removed and boiled in 10\% $\mathrm{KOH}$ solution for about 10 min until the muscles dissolved. Dissections and cleaning of genital structures were performed in distilled water. Final observations were done in glycerine. A few drops of blue paragon were added to the preparation in order to facilitate the observation of the ectodermic genital ducts. A Leica MZ16 stereomicroscope, equipped with a camera lucida for the drawing of the hind wing, tarsal segments and male genitalia, was used for observations. Photographs of the specimen were taken using a Nikon EOS 6OD camera attached to a Nikon SMZ 1500 stereomicroscope and further refined using Combine ZP software. For the genus and species described here, only two authors were selected for the authorship: M. Wang and A. Soulier-Perkins. 


\section{Abbreviations and terminology}

The terminology used for describing the morphology follows Soulier-Perkins (2001) and Bourgoin et al. (2015) for the venation of the tegmina. MaEP - median anterior extension of periandrium; PP - periandrium process; $\mathrm{PmL}$ - periandrium membranous lobe; PRs1 - periandrium rounded structure 1; PRs2 - periandrium rounded structure 2; VaPA - ventral anterior process of aedeagus; $\mathrm{VpPA}$ - ventral posterior process of aedeagus.

\section{TAXONOMY}

\section{Family Lophopidae Stål, 1866 Genus Silvispina M. Wang \& Soulier-Perkins, gen. $\mathbf{n}$.}

ZooBank taxon LSID: 61B27F49-4706-4FEB-ABC3-0F576F719F28

Type species. Silvispina changpotou M. Wang \& SoulierPerkins, sp. n., by present designation.

Diagnosis. This genus has the typical metatibia of the Sarebasa+ group with numerous small spines close together at its apex, but it can be quickly distinguished from all other known lophopid genera by the first segment of its tarsi bearing numerous small spines (more than 60) toward its apex. The shape and size of these spines are comparable to those at the apex of the tibia.

Description. Head. In dorsal view, head including compound eyes distinctly narrower than pronotum (Figs 1A, C). Vertex slightly longer than wide, length of vertex in midline shorter than width of head including compound eyes (Fig. 1C); all margins carinate and the lateral ones slightly elevated, anterior and posterior margins convex anteriorly, respectively, gently and strongly curved; median carina present and clearly visible. In lateral view, compound eyes well developed, rounded, callus present postero-ventrally (Fig. 1B). Ocelli present. Antennae with pedicel bulbous and foramen not touching the compound eyes (Figs 1B, D). Ocellar and genal carinae absent (Fig. 1B). In frontal view, frons distinctly longer than wide, slightly broader on its $1 / 3$ bottom part; fronto-clypeal margin almost straight, lateral margin carinate, sublateral carinae present, parallel over most of their length, fused together just bellow the frontovertex margin and not reaching the fronto-clypeal suture, weak median carina present (Fig. 1D). Clypeus strongly carinate laterally with median carina elevated (Fig. 1D). Rostrum long, reaching metacoxa.

Thorax. Pronotum shorter than vertex at the middle; anterior margin protruding medially and anteriorly rounded, lateral margins oblique, posterior margin straight; median area clearly delineated by the lateral carinae, median carina present but weak, presence of a dimple on each side of the median carina (Fig. 1C). Mesonotum longer than pronotum in middle line, tricarinate, lateral carinae diverging slightly posteriorly (Fig. 1C).

Wings. Tegmina relatively broad with the length less than 3 times its maximum width; costal and postclaval margins almost parallel, apical margin rounded, anterior cubital area margin slightly ampliated. Costal area broad with numerous transverse veins; basal cell longer than wide, veins $\mathrm{ScP}+\mathrm{R}, \mathrm{MP}$ and $\mathrm{CuA}$ separated from base,
$\mathrm{ScP}+\mathrm{R}$ bifurcating first then $\mathrm{MP}$ and $\mathrm{CuA}$ last, $\mathrm{RP}$ and $\mathrm{MP}_{3+4}$ bifurcating at the same level, Pcu and $\mathrm{A}_{1}$ fused in apical half of clavus (Fig. 1A). Hind wing wider than tegmina, anal lobe present, longitudinal veins present, radial and cubital areas containing numerous terminal veins (Figs 1E, 2), respectively, 6 and 9.

Legs. Moderately long, pro and mesothoracic femora and tibiae flattened but not foliaceous (Figs 1F, G). Metatibia broadening from base to apex (Fig. 1E), bearing 3 lateral spines and numerous small apical spines organized in a large apical band, first metatarsal segment thick at apex, bearing numerous small spines (more than 60) with a few a little larger and located at the very tip and on both sides (Fig. 1H). Just before the spines, a very small area, restricted to one side, is covered by numerous small setae. Second metatarsal segment small and without spines as in all Lophopidae (Fig. 1I).

Male terminalia. Anal tube long, increasing in width from the point of insertion of the epiproct (Figs 3A, C). Gonostyli bearing a small hook-like process at its tip (Figs 3A, B). In lateral view, pygofer with posterodorsal margin $\mathrm{V}$-shaped and truncated posteriorly, posterior margin with a small indentation ventrally just before a small ventral process oriented posteriorly, ventral margin almost straight (Fig. 3A).

Etymology. The name refers to the numerous small spines present on the metatibia and first metathoracic tarsus (Fig. 1H), both seem to bear a forest of spines "silvispina" from the latin "silva" forest and "spina" spine. The gender is feminine.

Distribution. China (Yunnan).

Remarks. The general features of this genus are similar to those of the genus Apia Distant, 1909 (Soulier-Perkins, 1998: Fig. 30), but differs in (1) the presence of a median carina on the pronotum, which is absent in Apia and (2) metatibia bearing numerous small spines apically (Fig. 1H), whereas in Apia there are no more than 12 large spines.

\section{Silvispina changpotou M. Wang \& Soulier-Perkins, sp. $\mathbf{n}$.}

(Figs 1-3)

ZooBank taxon LSID:

AFA3E2A8-9DFC-461E-884F-8F35BF36A7D8

Diagnosis. The periandrium with a median extension (MaEP) on the anterior dorsal margin (Fig. 3D) and the two rounded structures (PRs1 \& PRs2) in which the aedeagus processes are locked are unique to this species (Fig. 3E).

Description. Length: male (including tegmina) $(\mathrm{N}=1)$ : $9.2 \mathrm{~mm}$.

Vertex 1.1 times longer in midline than broad at base. Frons 2.7 times longer in midline than broad at base, 1.9 times longer in midline than widest part. Pronotum 3.4 times longer at longest part than along midline, 0.8 times longer in midline than vertex, with four small rounded protuberances located, two on each lateral area. Mesonotum 1.5 times broader at widest part than long in midline. Tegmina 2.7 times longer than the width at the widest part. 

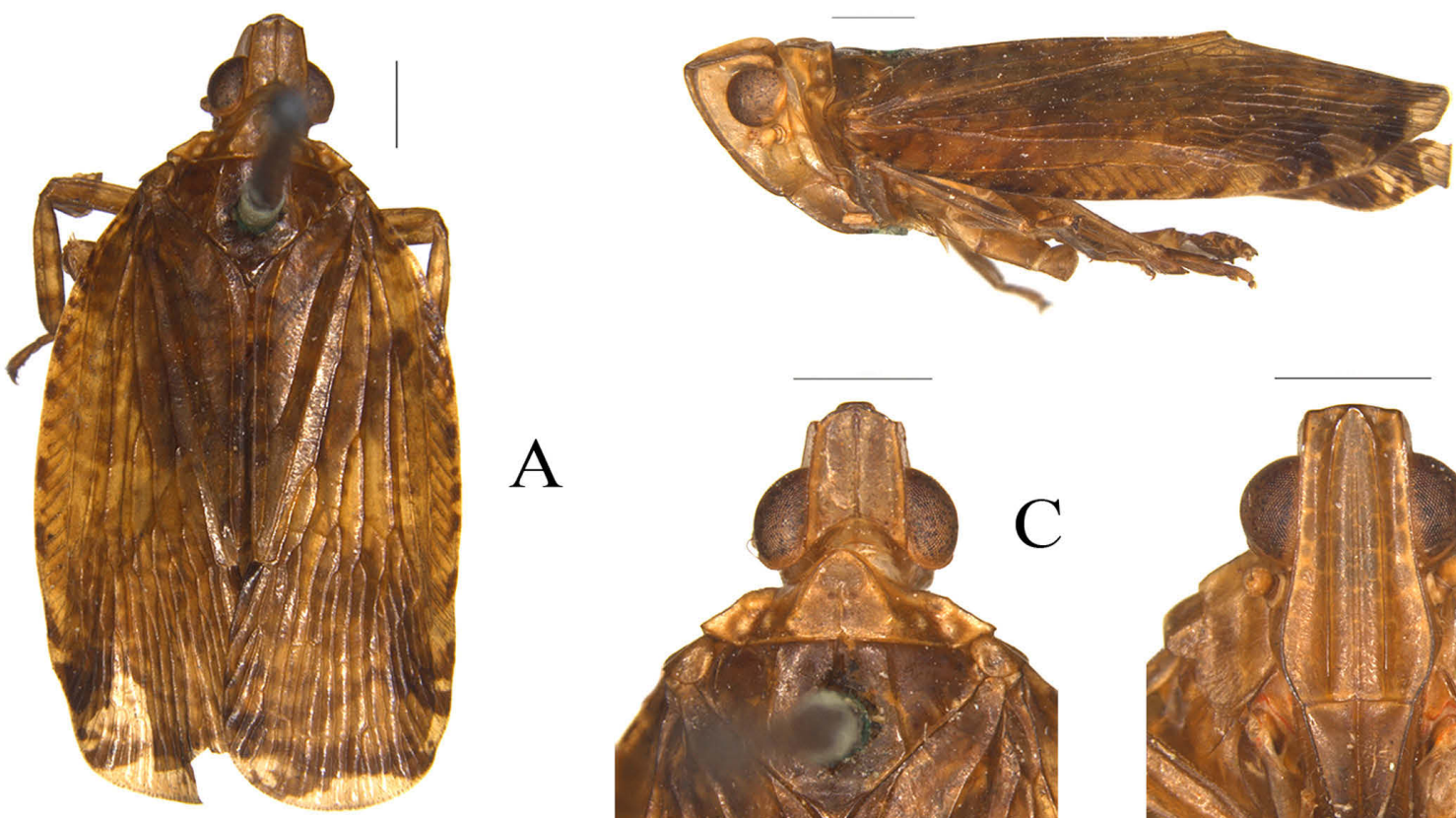

$\mathrm{B}$
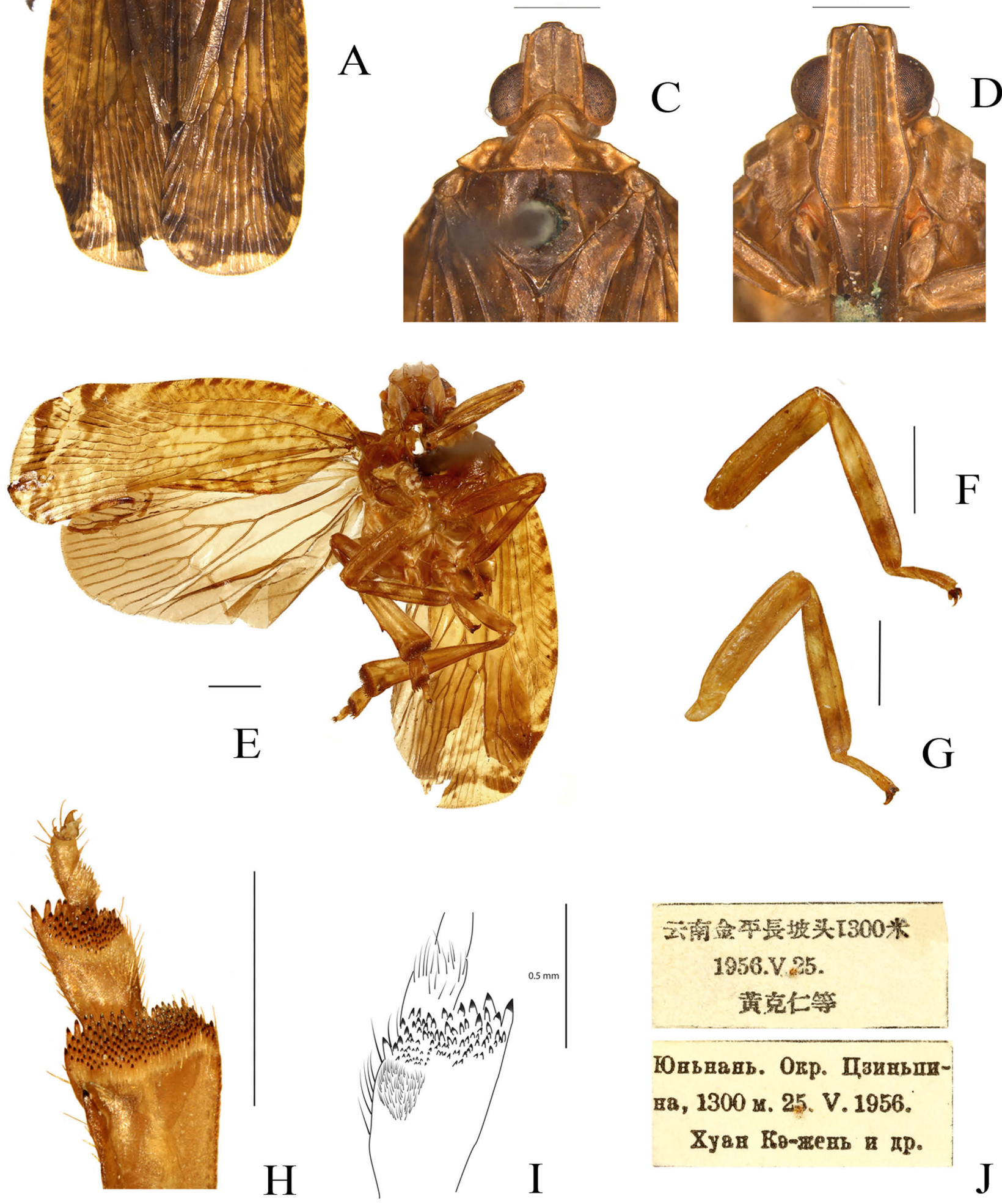

\section{0ньнавь. Окр. Пзиньих -} सа, 1300 м. 25. V. 1956 .

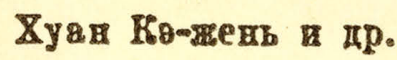

Fig. 1. Silvispina changpotou M. Wang \& Soulier-Perkins, sp. n., holotype, $\widehat{\jmath}$. A - habitus, dorsal view; B - habitus, lateral view; C - head and thorax, dorsal view; D - frons and clypeus, oblique ventral view; $E$ - habitus, ventral view; $F$ - fore leg; $G$ - middle leg; $H$ - apical part of metatibia and tarsal segments, ventral view; I - metatarsal segments, $3 / 4$ ventral view; $\mathrm{J}$ - labels. Scale bars $\mathrm{A}-\mathrm{H}=1 \mathrm{~mm}$. 


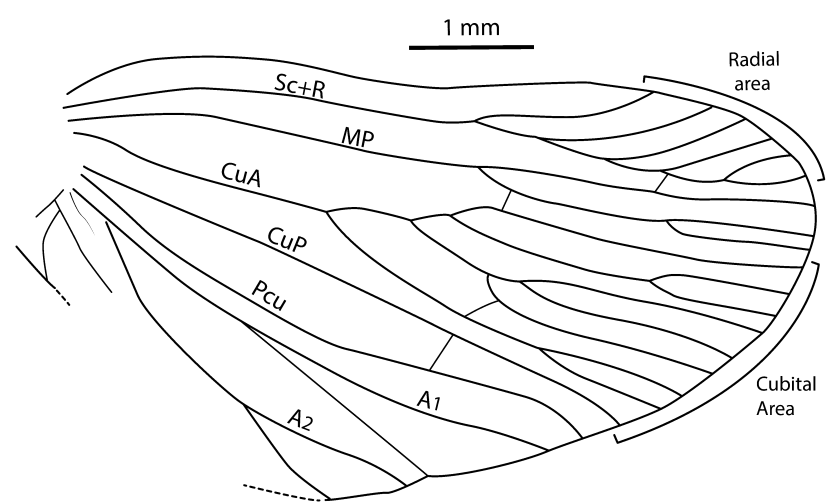

Fig. 2. Hindwing of Silvispina changpotou M. Wang \& SoulierPerkins, sp. n.
Coloration. Vertex tawny, anterior margin, lateral margins and median carina brown (Fig. 1C). Compound eyes yellowish black (Fig. 1C). Ocelli tawny. Gena in lateral view tawny (Fig. 1B). Frons tawny, anterior margin, lateral margins and sublateral carinae all brown, median carina tawny (Fig. 1D). Clypeus dark brownish, lateral carinae brown, median carina tawny (Fig. 1D). Pronotum tawny (Fig. 1C). Mesonotum and tegulae brown (Fig. 1C). Tegmina tawny, with several short, irregular brown markings along the costal margin; along the margin in the radial area the brown marking is larger; the tip of the tegmina, within the end of radial area and all median area, is paler and underlined by a darker brown band (Fig. 1A). Legs

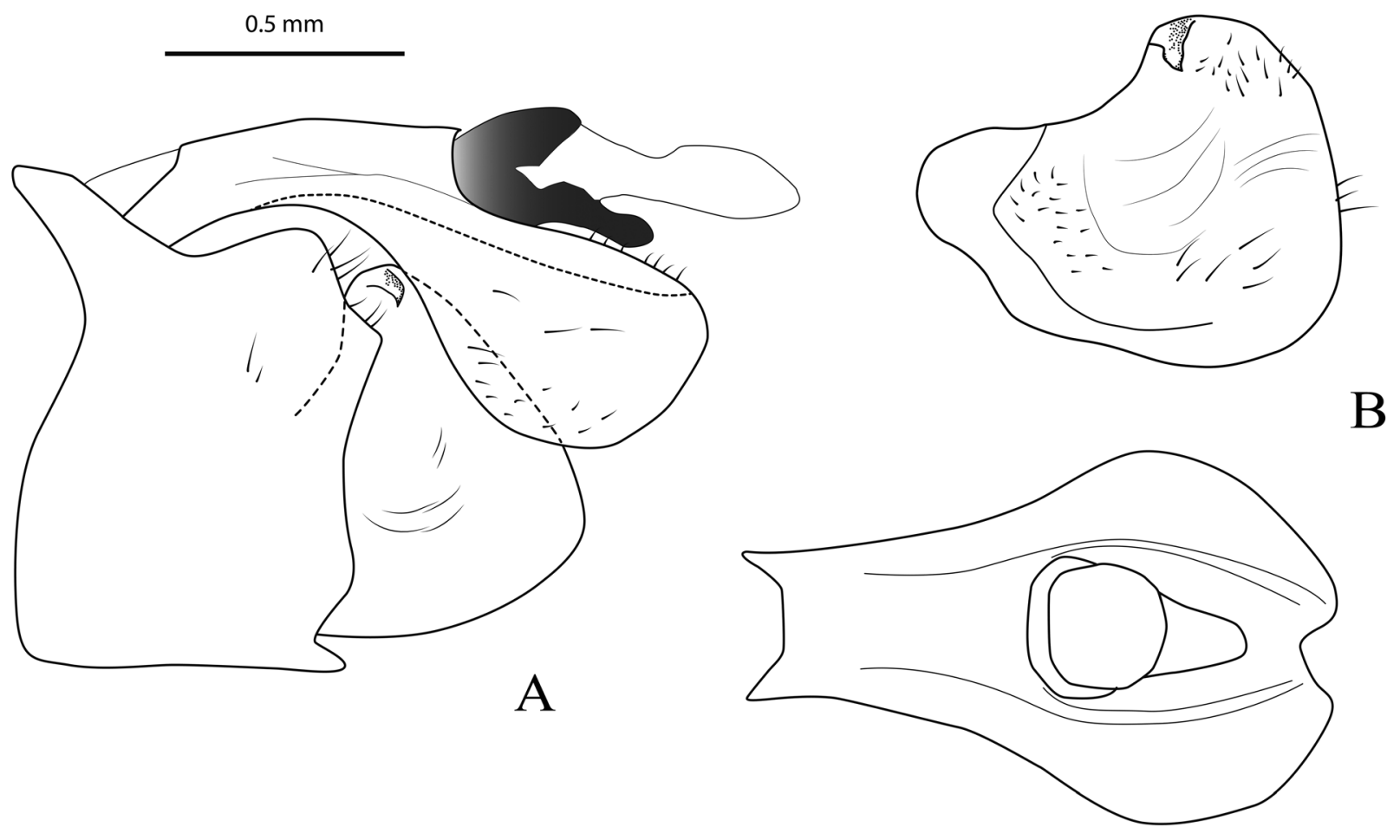

$0.5 \mathrm{~mm}$

$\mathrm{C}$
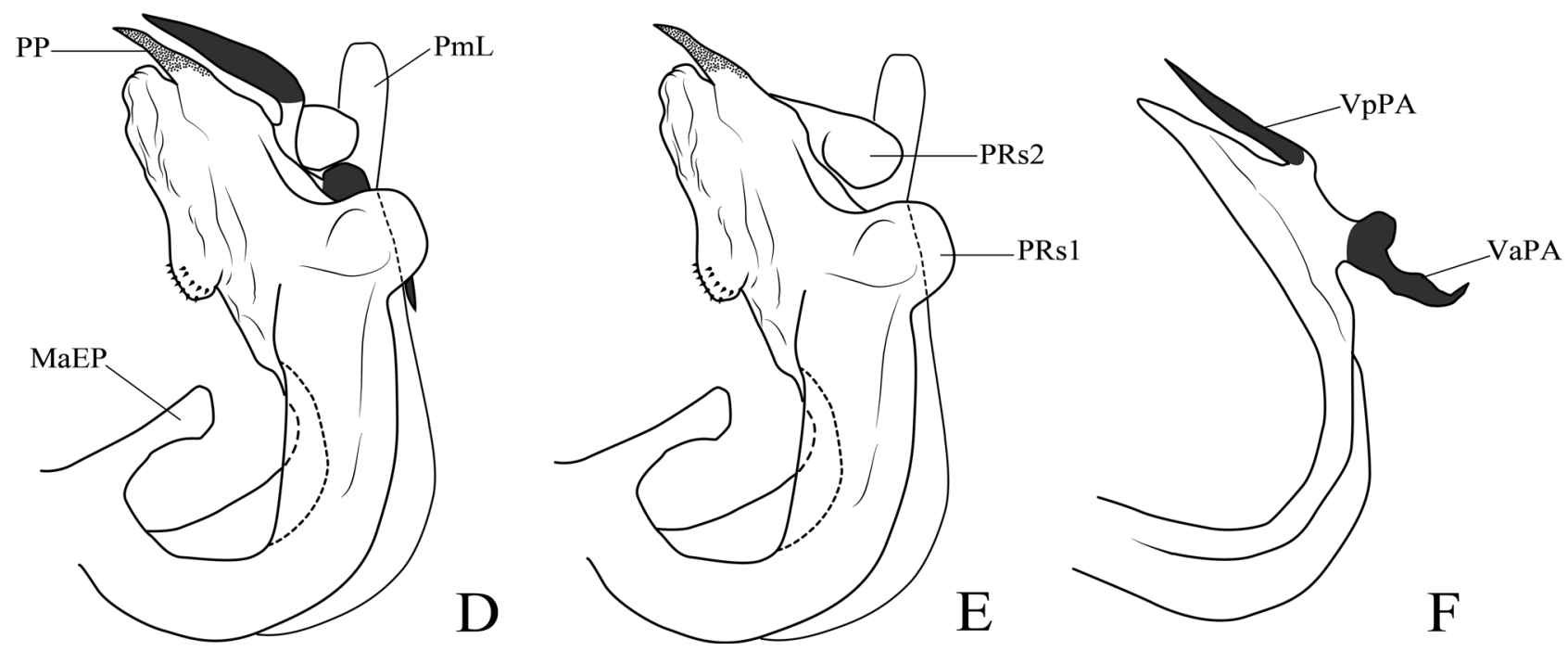

Fig. 3. Silvispina changpotou M. Wang \& Soulier-Perkins, sp. n., male terminalia (holotype). A - male terminalia, lateral view; B - gonostylus, lateral view; C - anal tube, dorsal view; D - phallic complex, lateral view; E - periandrium, lateral view; F - aedeagus, lateral view. 
tawny, pro and mesothoracic tibiae bearing weak brown circular marks (Figs 1F, G), the tip of lateral and apical spines black.

Male terminalia. Anal tube in lateral view obviously expanded in apical half (Fig. 3A), in dorsal view enlarged apically and spatulate, longer than width at widest part, apical margin very weakly concave in the middle (Fig. $3 \mathrm{C}$ ). In lateral view, periandrium bearing a median process on the anterior part of its dorsal margin (MaEP), dorsal margin strongly curved, which brings the apex of the periandrium towards the pygofer; it finishes in a rounded membranous part and bears a pair of processes (PP) pointing dorso-caudad (Fig. 3D). Ventral margin of periandrium strongly curved towards its apical part like the dorsal margin, two pairs of large rounded structures (PRs1 \& PRs2), in which the processes of the aedeagus are locked (Fig. $3 \mathrm{E})$. The ventral margin of periandrium finishes medially in a rounded membranous lobe $(\mathrm{PmL})$. Aedeagus prolonged beyond insertion of processes, sharp apically (Fig. $3 \mathrm{~F}$ ); anterior ventral processes of aedeagus present (VaPA), short and curved, locked in the first rounded structure of periandrium, apex of processes oriented ventro-laterally (Figs 3D, F); posterior ventral processes of aedeagus present (VpPA), gradually decreasing in size towards their pointed apices, which are oriented dorso-anteriorly like the periandrium processes, and are locked into the second rounded structure (PRs2) of the periandrium (Figs 3D, F).

Type material. Holotype: $1 \hat{\delta}$ (NWAFU). Translation of Chinese label: "China, Yunnan Province, Jinping, Changpotou, 1300 m, 25-V-56, coll. Keren Huang". Translation of Russian label: "Yunnan, near Jingping, 1300 m, 25.v.1956, Huang Ke-ren and others". The geographic coordinates of Changpotou are $22^{\circ} 57^{\prime} \mathrm{N}$, $103^{\circ} 18^{\prime} \mathrm{E}$.

Type locality. China, Yunnan, Jinping, Changpotou.

Etymology. The locality where the specimen was found is Changpotou. It is directly used as the species name as a noun in apposition to the generic name.

\section{DISCUSSION}

This new genus from Yunnan Province in China is unique within the Lophopidae since it is the only one with a large number of small spines on the apex of the first metatarsal segment.

Based on the shape and ornamentation of the metatibia and first tarsal segment, the genera of Lophopidae are classified in two subfamilies, the Menoscinae and Lophopinae (Emeljanov, 2014). In his key, the alternatives are as follows:

Menoscinae: "Plantar surface of basitarsus is covered with teeth and the apex of hind tibia with more than 10 large teeth".

Lophopinae: "Plantar surface of basitarsus covered with dense brush of papillae or microplatellae, separate teeth situated at sides of apex. Whole apex of hind tibia or only its lateral parts with numerous narrow (elongate) teeth densely arranged in transverse rows".

The genus Silvispina fits into neither of these two subfamilies and we propose placing it as incertae sedis in the Lophopidae. In 2001, Soulier-Perkins proposed a phylo- geny based on 73 morphological characters and divided the family into four natural groups: Carrionia ${ }^{+}, \mathrm{Makota}^{+}$, Sarebasa $^{+}$and Bisma ${ }^{+}$. Sarebasa ${ }^{+}$was supported by two synapomorphies, the apex of the metatibia bearing numerous small spines and the first segment of the metathoracic tarsus bearing a pad of microsetae. Silvispina clearly only shares the first synapomorphy with this group. However, it does not possess the presumed plesiomorphic state either (the simple absence of a pad of microsetae as observed in the other groups). In Silvispina, there is a dense concentration of small spines where a part of the pad should be, plus a small area covered by numerous setae on the external side just before the area with the spines. We cannot say if the evolution of the morphological characters on this tarsal segment went from no ornamentation with only a few stout spines organized in an area on its apex, to an intermediate form with a small area covered with setae and an apex where the spines have proliferated but are reduced in size, to a third type in which a large pad of microsetae is framed apically by only few small spines. The characters on this tarsal segment have to be carefully examined and their homology determined. Their delineation should be specified and new states for these characters should be coded and included in a new matrix for a cladistics analysis. Such an analysis would clarify the phylogenetic position of Silvispina M. Wang \& Soulier-Perkins, gen. n. in the Lophopidae and reveal its sister group. Currently there is a need for the classification proposed by Emeljanov (2014) to be scrutinized and revised. The position and status of some genera should be clarified. For example, he erected to genus level the subgenus Acarnana Emeljanov, 2012 without giving the reasons for this change.

Note: When compiling Table 1, we came across the genus Ridesa Schumacher, 1915, and questioned its placement in the classification. Pictures of the syntypes are now available from the website Digitization of Historic Museum Collections of Taiwan deposited in foreign countries (http://dhmct.digital.ntu.edu.tw/chv_e.htm). From these pictures, it clearly appears that Ridesa should be removed from the Lophopidae and placed in the Achilidae. Ridesa is therefore hereby placed as a genus incertae sedis in the Achilidae until the specimens are examined.

ACKNOWLEDGEMENTS. This study was supported by the National Natural Science Foundation of China (31372234), the Pilot Project of Standardized Curation, Data Integration and Resource Sharing of Zoological Collections (2005DKA21402) by the Ministry of Science and Technology of China, and China Scholarship Council.

\section{REFERENCES}

AmORIM D.S. 1982: Classificação por sequenciação: Uma proposta para a denominação dos ramos retardados. - Rev. Bras. Zool. 1: 1-9.

BourgoIn T. 2015: FLOW (Fulgoromorpha Lists On the Web): A World Knowledge Base Dedicated to Fulgoromorpha. Version 8, updated (4 Nov. 2015). URL: http://hemiptera-databases. org/flow/ (last accessed 4 Nov. 2015).

Bourgoin T., Wang R.R., Asche M., Hoch H., Soulier-Perkins A., Stroiński A., YAP S. \& Szwedo J. 2015: From micropterism 
to hyperpterism: recognition strategy and standardized homology-driven terminology of the forewing venation patterns in planthoppers (Hemiptera: Fulgoromorpha). - Zoomorphology 134: 63-77.

EMELJANOv A.F. 2014: On the subdivision of the family Lophopidae (Homoptera, Auchenorrhyncha: Fulgoroidea) on the subfamilies and tribes with description of two new tribes. - Entomol. Rev. 94: 208-210.

GNezDiLov V.M. 2009: A new subfamily of the planthopper family Ricaniidae Amyot et Serville (Homoptera, Fulgoroidea). Entomol. Obozr. 88: 807-812.

Metcalf Z.P. 1955: Part 17 Lophopidae. In China W.E. \& Metcalf Z.P. (eds): General Catalogue of the Homoptera, Fascicle IV Fulgoroidea. North Carolina State College, Raleigh, pp. 1-75. Soulier-Perkins A. 1998: The Lophopidae (Hemiptera: Fulgoromorpha): Description of three new genera and key to the genera of the family. - Eur. J. Entomol. 95: 599-618.
Soulier-Perkins A. 2001: The phylogeny of the Lophopidae and the impact of sexual selection and coevolutionary sexual conflict. - Cladistics 17: 56-78.

Soulier-Perkins A. \& Stroiński A. 2015: A new lophopid genus as another piece in the biogeographical history puzzle of the family in the Sunda Shelf (Hemiptera: Fulgoromorpha: Lophopidae). - Zootaxa 4006: 586-600.

STÅL C. 1866: Hemiptera Homoptera Latr. Hemiptera Africana 4. Officina Norstedtlana, Stockholm, $276 \mathrm{pp}$.

Stroiński A. \& Soulier-Perkins A. 2015: A new lophopid genus (Hemiptera: Fulgoromorpha) corroborates the family phylogeny and historical biogeography. - Ann. Zool. 65: 269-285.

Received November 23, 2015; revised and accepted January 12, 2016 Published online February 25, 2016 